\title{
In situ Sintering of Ni Nanoparticles by Controlled Heating
}

\author{
Misa Matsuno*, Cecile S. Bonifacio*, Andrew M. Thron*, Jorgen Rufner,* Troy B. Holland,* \\ and Klaus van Benthem* \\ *Department of Chemical Engineering and Materials Science, University of California, Davis, 1 \\ Shields Ave., Davis. CA, 95616
}

Sintering describes the consolidation of individual (nano) particles to form a dense microstructure through the application of heat, pressure, electric fields, etc. [1] Electric fieldassisted sintering (EFAS) has demonstrated that a combination of electrical fields and appropriate heating rates can lead to accelerated densification with a significant suppression of grain growth [2]. Despite the abundance of sintering studies reported in the literature and the wide application of EFAS, the atomic scale consolidation mechanisms under electrical fields and heating rates during EFAS remain mostly unclear [2].

In situ heating of soft agglomerates of nanoparticles was carried out with a Protochips Aduro heating holder inserted into a Jeol JEM 2500SE transmission electron microscope. Nickel particles with diameters of $20 \mathrm{~nm}$ were dispersed in ethanol and drop-casted on the holey carbon films mounted onto the Aduro MEMS heating device. The particles were gradually heated to a maximum temperature of $550^{\circ} \mathrm{C}$ while the contact area between the particles was observed by TEM.

Figure 1 shows two TEM micrographs of a soft agglomerate of several Ni particles that were extracted from the recorded video for temperatures of $300^{\circ} \mathrm{C}$ (Figure 1a) and $525^{\circ} \mathrm{C}$ (Figure 1b), respectively. EELS measurements of the $\mathrm{O} \mathrm{K}$ and $\mathrm{Ni} \mathrm{L}_{2,3}$ absorption edges recorded before the heat treatment revealed $\mathrm{NiO}$ layers on the surface of the individual particles with an approximate thickness of $1.5 \mathrm{~nm}$ (see Figure 1a) [3]. During the heating experiment neck formation between the particles and subsequent growth was observed (see Figure 1b). The formation of necks at the contact area between two particles occurs mostly through surface diffusion during the first stage of sintering. The dihedral angle between the particles was measured from the TEM images as demonstrated in Figure 1a. The evolution of the dihedral angle is plotted as a function of time and temperature in Figure 2. From this result we conclude that significant mass transfer into the contact area, i.e. neck growth, occurred around $450^{\circ} \mathrm{C}[3]$.

During the annealing experiment, the initially spherical nanoparticles became faceted as the temperature increased over time. Furthermore, reduction of the passivating oxide layer was observed starting around $350^{\circ} \mathrm{C}$ [3]. Thermodynamic calculations of Gibbs Free Energies are currently underway to further investigate the observed reduction of the $\mathrm{NiO}$ layer that precedes neck formation and subsequent consolidation during EFAS.

[1] Suk-Joong L. Kang, Sintering: densification, grain growth, and microstructure (2005)

[2] W. Chen, U. Anselmi-Tamburini, J.E. Garay, J.R. Groza, Z.A. Munir; Materials Science and Engineering A, 394, (2005)

[3] M. Matsuno, C. S. Bonifacio, T. B. Holland, and K. van Benthem, submitted for publication

[4] The authors acknowledge financial support by UC Davis start-up funds. MM was financially supported by the Japan Student Services organization (JASSO). 

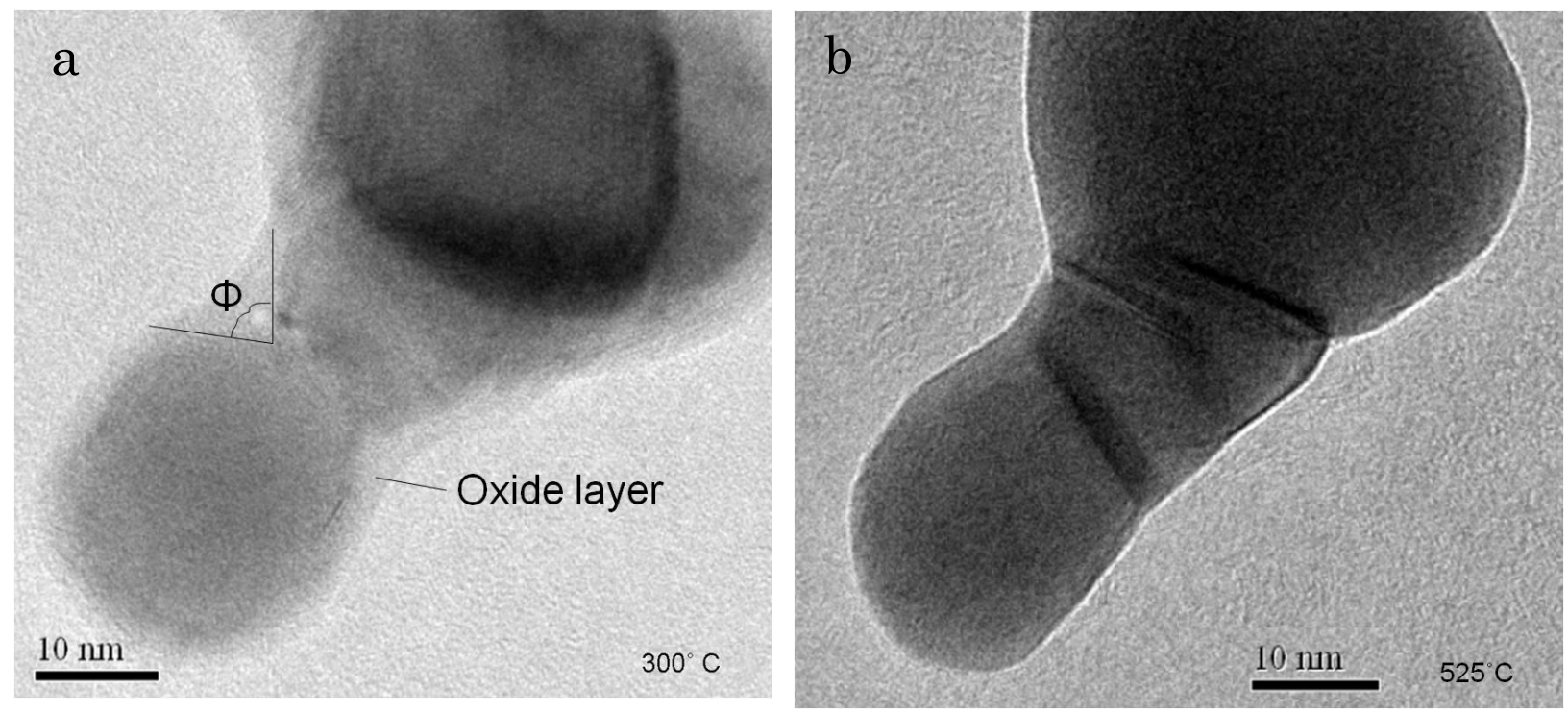

Figure 1. TEM images of the $20 \mathrm{~nm}$ Ni nanoparticles at early stages of sintering at $300^{\circ} \mathrm{C}$ in panel $\mathbf{a}$ and after coalescence at $525^{\circ} \mathrm{C}$ in $\mathbf{b}$. Images were extracted from a video clip acquired during in situ annealing [3].

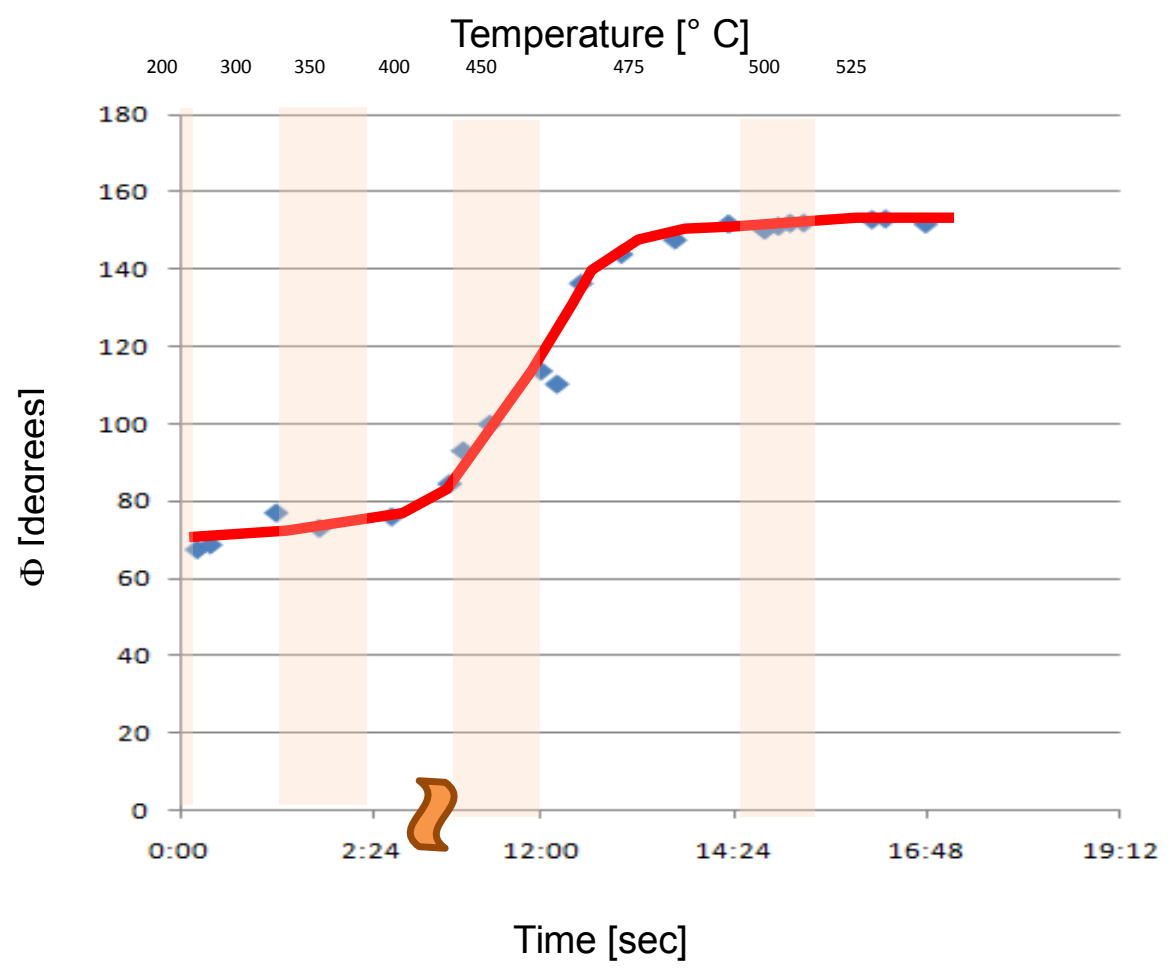

Figure 2. Evolution of dihedral angle $\Phi$ as a function of time and temperature. 